\title{
A Agência Nacional de Educação e Formação de Adultos (ANEFA): Um marco na europeização da agenda pública do setor
}

\author{
Rosanna Barros \\ Universidade do Algarve, Portugal
}

\begin{abstract}
Resumo
O texto apresenta o enquadramento sociopolítico com que foi criada a primeira instituição nacional de representação pública oficial para a educação de adultos. Demonstra-se que esta Agência Nacional de Educação e Formação de Adultos (ANEFA), apesar de ter conhecido uma existência curta, e normativamente precária, representou um marco fundamental para implementar as atuais características de desenvolvimento do setor. Argumenta-se que o seu papel consistiu em alterar os termos da regulação educacional instituída, na medida em que, a partir da sua atuação, foram transnacionalmente estabelecidas em contexto português as bases da governação pluriescalar da "nova EFA" que, sustentamos, caracteriza hoje o campo.
\end{abstract}

Palavras-chave

Educação de adultos; Novas ofertas educativas; Governação pluriescalar; Políticas educacionais

\section{Introdução}

A Resolução do Conselho de Ministros (RCM) n. ${ }^{\circ}$ 92/98, de 25 de junho, introduziu a ideia de que compete à educação e formação de adultos contribuir para o imperativo nacional de integração da formação social portuguesa "na sociedade do conhecimento globalizada", dando resposta às "mutações da vida profissional no mundo actual", especialmente quando 
largas camadas da população activa portuguesa, jovem e adulta, quer no que se refere a níveis educativos e culturais, quer no que se refere a níveis de qualificação profissional, coloca[m] Portugal numa situação particularmente desfavorável, tanto em termos de coesão social interna e de cidadania activa como de condições de empregabilidade e competitividade (RCM n. ${ }^{\circ}$ 92/98).

Assim, foi através desta Resolução, articulada com o Documento de Estratégia para o Desenvolvimento da Educação de Adultos - Uma Aposta Educativa na Participação de Todos, de 1998 (Documento de Estratégia), criado para o setor, que se estabeleceram os termos segundo os quais se deveria criar um programa de desenvolvimento estratégico de educação e formação de adultos, que deveria, por sua vez, englobar o conjunto de processos de aprendizagem, formais e não formais, combinando uma lógica de serviço público com uma lógica de programa e propiciando o estabelecimento alargado de parcerias. Este programa foi traduzido normativamente no Projecto de Sociedade S@ber +, Programa para o Desenvolvimento e Expansão da Educação e Formação de Adultos, 19992006, de 1999 (Programa de Acção S@ber +), no qual foi concebido um conjunto diverso de atribuições de que destacamos, pelo potencial que continham para o alargamento do campo, especialmente: a criação, por um processo participado, de uma Agência Nacional de Educação e Formação de Adultos; a articulação estratégica com as autarquias, escolas, parceiros sociais e entidades privadas visando a elaboração de planos e unidades territoriais de educação de formação de adultos; a organização e animação de uma rede nacional de animadores locais; e a construção experimental e gradual de um sistema de validação formal dos saberes e competências informais.

Deste modo, para lançar e executar este projeto foi criado, pela mesma RCM, um Grupo de Missão para o Desenvolvimento da Educação e Formação de Adultos (GMEFA), que foi tutelado pelo Ministério da Educação e pelo Ministério do Trabalho e da Solidariedade, tendo sido composto por funcionários de ambos os Ministérios e coordenado por Alberto Melo. Nas palavras de Melo (2001), o GMEFA tinha "dois grandes objectivos: criar a Agência Nacional de Educação e Formação de Adultos (ANEFA) e colocar os alicerces de uma nova oferta, mais acessível, flexível e adequada" (pp. 105106). Não obstante ser possível retirar desta RCM, como notam Lima, Afonso, e Estêvão (1999), que este projeto deveria, quer pelo seu elevado potencial 
estratégico de desenvolvimento do setor, quer pela possibilidade de participação nas várias fases de consulta e experimentação, ter propiciado ainda a criação de "estruturas maleáveis de organização, com soluções diversificadas e inovadoras em termos de oferta educativa e de articulação institucional" (p. 42), na realidade houve aspetos que, tendo sido sugeridos e contemplados no Documento de Estratégia, ficaram aquém das expectativas aquando da redação desta RCM. De acordo com Melo (2006), "o que aconteceu na realidade foi o tradicional 'processo de deitar abaixo' que acontece sempre que se tomam decisões sobre a educação de adultos em Portugal" (p. 182).

\section{Construindo uma Agência, reconstruindo um setor: A agenda política nacional para a EFA na viragem para 0 século $X X I$}

Ora, foi com este enquadramento, e a partir daqui, que o Grupo de Missão solicitou, por um lado, à Unidade de Educação de Adultos (UEA) da Universidade do Minho (UM), a realização de um estudo "relativo à criação e organização de uma estrutura nacional de desenvolvimento e coordenação da educação e formação de adultos" (Lima et al., 1999, p. 9), e, por outro, ajudou o poder político a iniciar a construção de um $3^{\circ}$ setor autónomo - mas complementar do sistema escolar de cursos noturnos e das ações de formação profissional -: o sistema EFA, tão desescolarizado quanto possível, mas capaz de assegurar a possibilidade de certificação oficial, assim como a participação, como entidades formadoras, de uma vasta gama de instituições (Melo, 2001, p. 106).

Surgiram assim, no ano de 1999, os frutos diretamente resultantes destas medidas, tais como o estudo encomendado (elaborado por uma equipa de especialistas constituída para o efeito) que foi apresentado ao Grupo de Missão em janeiro de 1999, contemplando um vasto conjunto de propostas para a construção de um modelo institucional para a ANEFA. Tratou-se de propostas regidas pelos princípios de responsabilização do Estado e valorização do domínio público, pelo princípio de descentralização e autonomia e pelo princípio da representatividade e participação - três elementos que justificaram a opção pela Direção colegial, pela negociação e concertação (cf. Lima et al., 1999, pp. 42-79). 
Em abril de 1999, o Grupo de Missão apresentou então o Programa de Acção S@ber +. Tratou-se de um plano de ação do qual, basicamente, se esperaria, embora com moderado entusiasmo, a concretização das medidas políticas globais que, desde sempre, têm persistido em se pautar pela ausência, no panorama do agendamento político inerente à história portuguesa do campo da educação de adultos (Castro, Sancho, \& Guimarães, 2006). Como sublinhou Lima (2000), "este plano de aç̧ão e a Agência Nacional podem-se tornar a última oportunidade para preparar um período de transição para o próximo século e milénio onde, finalmente, teríamos uma política pública intencionalmente orientada para a constituição e desenvolvimento de um sistema de educação contínua de adultos em Portugal" (p. 11).

Deixando claro o tipo de mandato equacionado politicamente para o futuro de um setor que se pretendia renovado, os dois responsáveis políticos à data mais diretamente envolvidos na criação deste subsistema em Portugal - a Secretária de Estado da Educação e Inovação e o Secretário de Estado do Trabalho e da Formação - esclareceriam, respetivamente, que "aquilo que se pede à educação e formação de adultos, hoje em dia, é ter respostas adequadas à diversidade das situações e poder responder a grupos-alvo prioritários" (Ana Benavente, cit. em Melo, Matos, \& Silva, 2001, p. 9), e que "o essencial do problema, em particular na população não-jovem, é simultaneamente de qualificação profissional e de capacitação escolar. Logo, é preciso encontrar respostas articuladas entre o trabalho que se faz no domínio da educação ao longo da vida, e o que se faz na formação profissional contínua" (Paulo Pedroso, cit. em Melo et al., 2001, p. 9).

Deste modo, o Programa de Acção S@ber +, com que se veio a iniciar a agenda do século XXI, mais do que atualizar as Propostas e os Relatórios precedentes ${ }^{1}$, veio apresentar e disseminar uma nova conceptualização do campo que deixou, por definição decretada oficialmente, de ser de Educação de Adultos (EA) para passar a ser de Educação e Formação de Adultos (EFA), entendendo-se por tal "o conjunto das intervenções que, pelo reforço e complementaridade sinérgica com as instituições e as iniciativas em curso no domínio da educação e da formação ao longo da vida, se destinam a elevar os níveis educativos e de qualificação da população adulta e a promover o desenvolvimento pessoal, a cidadania activa e a empregabilidade" (Melo et 
al., 2001, p. 11), tendo sido a sua estratégia e sentido "a promoção da articulação entre os domínios da educação, formação e emprego, através do reconhecimento dos processos de aprendizagem não formais, nomeadamente os ligados aos contextos de trabalho" (Melo et al., 2001, p. 6).

Nesta transição conceptual, que foi apresentada como sendo o libertar da área da EA, tutelada tradicionalmente pelo Ministério da Educação - que se encontraria prisioneiro de uma visão "algo incompleta ou mesmo redutora, já que a 'educação de adultos' nas sociedades de hoje não pode e não deve esquecer ou deixar de fora as questões relevantes e críticas da empregabilidade, do emprego, do trabalho, da formação qualificante e de qualidade para todos" (Trigo, cit. em Melo et al., 2001, p. 5) -, detetámos, efetivamente - salvaguardando, não obstante, as várias formas segundo as quais se pode pretender não deixar de fora as referidas questões relevantes ${ }^{2}$ -, um certo potencial na ideia, de facto inovadora, que "tem de haver respostas integradas, e as entidades têm de se articular: aquilo que significa avanço profissional tem de ser também avanço em termos de educação, de formação geral da pessoa" (Melo et al., 2001, p. 11). Mas o que nos parece de absoluta relevância enfatizar é que se trata de um potencial que só se reverte em impacto significativo para o campo (entenda-se para os seus atores principais: educandos adultos e educadores, compreendendo-se aqui os vários elementos das equipas técnicas criadas posteriormente, tais como os profissionais de reconhecimento e os formadores) se - e unicamente se as modalidades de educação, certificáveis ou não, não se subsumirem nas modalidades certificáveis de formação profissional e vocacional, caso em que estaríamos em condições de assistir a uma interessante "recomposição do sector" (Rothes, 2005).

Contudo, o que nos foi dado a ver seria a "mutação deste subsistema" (Barros, 2009), já de si diminuído, em algo efetivamente novo mas que em nada viria a contribuir para a criação de um mundo melhor, ou seja, mais justo e mais democrático (Caride, Peres, Sanjurjo, Ortega, \& Pose 2009) - que é, afinal, o primeiro e último desiderato, desde sempre, de uma conceção de educação de adultos ampla e criticamente orientada (UNESCO, 1976), que, ao ser relançada, como se prometeu em início de ciclo de governação socialista, no ano de 1996, deveria sê-lo, desde a nossa ótica, para aprofundar esta visão, e não para a bloquear, e isto com o propósito maior de, 
como defende Guimarães (2008), "sublinhar e relevar a interdependência solidária entre as pessoas, entre os povos, as sociedades, na relação entre o global e o local, e na eco-esfera no seu todo" (p. 16).

\section{Itinerários do lançamento de uma nova oferta educativa pública}

Objetivamente, o Programa de Acção S@ber + apresentou um conjunto diverso de finalidades e objetivos que enformaram a base dos princípios gerais para as ações que coube à ANEFA executar. Estas ações foram estruturadas segundo três eixos de intervenção, designadamente: a motivação das pessoas adultas para a procura; a oferta adequada, flexível e diversificada de educação e formação, por parte das entidades formadoras; e a formação de agentes. Ora, tendo-se apresentado formalmente como estando inscritas "no quadro da filosofia de cariz humanista" (Melo et al., 2001, p. 15), veio a ser paradoxal constatar a significativa valorização implícita de uma lógica de mercado que se traduziu na promoção de atividades destinadas a motivar uma procura para satisfazer uma oferta. Assim, no âmbito do primeiro eixo de intervenção, dirigido ao aumento da procura, a aposta foi feita numa forte e constante campanha de comunicação e na criação e apoio aos Clubes S@ber + (cf. Melo et al., 2001, pp. 29-32). Afigura-se fundamental, neste ponto, assinalar que estes Clubes, que foram pensados como "espaços de convívio, acolhimento, informação e orientação de adultos" (Melo et al., 2001, p. 30), parecem-nos ter sido, no panorama geral deste Programa, o coração de um sistema EFA com possibilidades, a partir daqui, de escapar a uma mera instrumentalização do setor para benefício da economia.

No segundo eixo de intervenção, que pretendeu diversificar a oferta, a aposta veio a ser maioritariamente orientada para a consolidação de um novo sistema EFA de estrutura modelar centrado no reconhecimento, validação e certificação dos resultados da autoformação da população adulta, priorizandose a criação das estruturas necessárias para permitir que os adquiridos informais fossem alvo de uma "análise rigorosa e reconhecimento formal, traduzidos numa validação oficial: creditação (outorga de créditos) com equivalência, parcial (dispensa de uma certa parte do percurso de formação) ou total (certificação, obtenção imediata de diploma oficial)" (Melo et al., 2001, p. 33). 
Por fim, o terceiro eixo de intervenção visou investir na "formação dos diferentes tipos de profissionais que serão responsáveis pela concretização do presente programa" (Melo et al., 2001, p. 39), agrupados em quatro categorias principais: organizadores locais; avaliadores de competênciaschave; formadores; e responsáveis de Clubes S@ber +. Nestes termos, previu-se, para a implementação (entre 1999-2006) do Programa de Acção S@ber +, um papel-chave a desempenhar pela ANEFA (cf. Melo et al., 2001, pp. 13-15), quer no incremento alargado de diversas parcerias com o terceiro setor, quer na promoção de múltiplas articulações com sistemas já existentes, tais como o sistema de formação profissional, o sistema escolar e o sistema nacional de certificação.

Foi deste modo que nasceu, finalmente, no panorama português, nas palavras de Antunes (2011a), "um esforço de criação de um sistema e uma política públicos, globais e integrados de educação e formação de adultos como projeto de sociedade" (p. 37), e que surgiu, no seu âmbito, uma Agência Nacional específica para este setor educacional. A ANEFA foi então criada, em setembro de 1999 (pelo Decreto-Lei n. ${ }^{\circ} 387 / 99$, de 28 de setembro), como instituto público dotado de personalidade jurídica, com autonomia científica, técnica e administrativa, e sob a tutela e superintendência dos Ministérios da Educação e do Trabalho e da Solidariedade. Nos termos deste articulado, a ANEFA, que foi colocada em regime de instalação por dois anos ${ }^{3}$, seria "concebida como estrutura de competência ao nível da concepção de metodologias de intervenção, da promoção de programas e projectos e do apoio a iniciativas da sociedade civil, no domínio da educação e formação de adultos, e ainda da construção gradual de um sistema de reconhecimento e validação das aprendizagens informais dos adultos" (cf. Decreto-Lei n. ${ }^{\circ}$ 387/99). Nesta linha de entendimento, foi-lhe imputado um conjunto de oito atribuições destinadas a expandir o setor, de entre as quais destacamos: a de celebrar contratos-programa com outras entidades públicas e privadas, investindo também na formalização de parcerias territoriais; a de construir um sistema de reconhecimento dos adquiridos da população adulta, visando a certificação escolar e profissional; e a de motivar, informar e aconselhar as pessoas adultas relativamente à possibilidade e oportunidade da aprendizagem ao longo da vida. 
No essencial, foram estas, portanto, as ações e medidas políticas com significado para o campo da - desde então publicamente designada 'educação e formação de adultos' que tiveram lugar em Portugal na primeira legislatura, iniciada em 1996, do Governo socialista, que, em outubro de 1999, seria reeleito, dando lugar ao XIV Governo Constitucional. O seu Programa de Governo reassumiu, assim, sem surpresas, as principais linhas de intervenção já iniciadas, tendo-se orientado a ação governativa por duas grandes apostas transversais: a sociedade da informação e do conhecimento e a igualdade de oportunidades. No âmbito das políticas sociais, a educação, formação e emprego reemergiriam como os eixos estruturantes da agenda política nacional para a educação, encarada como "absolutamente necessária para que possamos disputar a batalha da produtividade e da qualificação do emprego" (Programa do XIV Governo, 2000, p. 22), podendo-se encontrar, neste âmbito da atuação política, como uma das prioridades "o desenvolvimento da educação e formação de adultos" (p. 25), perspetivada como um elemento fundamental para "operar no terreno um conjunto de grandes transformações" (p. 28).

Pretendeu-se que estas grandes transformações fossem provocadas por doze propostas de ação, de que destacamos: o mandato atribuído à ANEFA no sentido de desenvolver um trabalho conjunto de promoção da educação e formação ao longo da vida, contribuindo para reformar o ensino recorrente; a meta de qualificar os trabalhadores portugueses de todas as gerações, formando, a partir de 2002, pelo menos $10 \%$ da força de trabalho em cada ano; o objetivo de promover a obtenção da escolaridade obrigatória nos cidadãos adultos através de modalidades que permitam essa certificação; e a intenção de alterar as regras de cofinanciamento da formação, promovendo a qualidade das ações e a estabilidade das instituições que a desenvolvem, novas oportunidades de acesso individual à formação e uma maior descentralização na tomada de decisão. Ora, durante a governação socialista, tornou-se, pois, particularmente visível a emergência de um hibridismo ambivalente nas orientações da política educativa para este subsistema, que, também aqui, combinou, como sustentam Teodoro e Aníbal (2006) para a educação em geral, "discursos de pendor construtivista numa perspectiva crítica com discursos apologistas de eficiência social que submete a utilidade da educação à produtividade económica" (p. 15). 
Foi com este enquadramento de fundo, e para dar prossecução a este mandato já implícito nas suas atribuições, que foram criadas, no âmbito da Comissão Instaladora da ANEFA, quatro equipas de projeto, designadamente: a equipa de projeto de reconhecimento e validação de competências (Despacho Conjunto n. ${ }^{\circ}$ 1092/2000, de 24 de novembro - DR n. ${ }^{\circ} 272$, II Série); a equipa de projeto de oferta de educação e formação de adultos e de sistema de educação e formação de adultos à distância (Despacho Conjunto n. ${ }^{\circ}$ 1112/2000, de 29 de novembro - DR n. ${ }^{\circ} 276$, II Série); a equipa de projeto de gestão administrativa e financeira (Despacho Conjunto n. ${ }^{\circ} 1113 / 2000$, de 29 de novembro - DR n. ${ }^{\circ} 276$, II Série); e a equipa de projeto de produção e gestão da informação e do conhecimento (Despacho Conjunto n. ${ }^{\circ}$ 1114/2000, de 29 de novembro - DR n. ${ }^{\circ}$ 276, II Série). Assim, tanto o ano de 2000 como o ano de 2001 foram marcados, sobretudo, pela entrada em cena do funcionamento da ANEFA, o que, segundo Santos Silva (2002), representou "um passo qualitativo fundamental na reorganização da oferta pública numa matéria tão decisiva para o nosso futuro quanto a qualificação da nossa população activa" (p. 67). Deste modo, seriam promovidas atividades destinadas, no essencial, a ir ao encontro da situação educacional da população ativa mediante a "criação de soluções flexíveis que articulem a educação e a formação, através de percursos organizados, a partir de processos de reconhecimento e validação de saberes adquiridos e de sistemas modulares de formação" (ANEFA, 2001c, p. 29).

A par do Ensino Recorrente de Adultos (ERA), Básico e Secundário, e da Educação Extra-Escolar (EEE), presentes no panorama português desde a Lei de Bases do Sistema Educativo de 1986 (LBSE - Lei n. ${ }^{\circ}$ 46/86, de 14 de outubro. Esta Lei veio a sofrer duas alterações: a primeira em 1997 e a segunda em 2005), a estruturação da nova oferta de EFA compreendeu, neste período, as seguintes modalidades: uma oferta de Cursos de Educação e Formação de Adultos (cursos EFA); uma oferta de Ações S@ber +; e uma oferta de Reconhecimento, Validação e Certificação de Competências (RVCC) - pelo que, como resultado das políticas públicas efetivadas pela ANEFA, se veio a constatar um real alargamento da rede nacional afeta ao setor e, portanto, antes de mais, uma expansão da diversificação da oferta, apesar da excessiva concentração de esforços apenas numa parcela da população adulta: a população ativa. 
Ora, sinteticamente, podem-se destacar algumas das principais diacríticas de cada uma destas novas possibilidades referentes ao sistema EFA. Assim, no respeitante à oferta de cursos EFA, o que sobressaiu, desde o início, como mais característico e inovador foi a sua conceção numa lógica de dupla certificação (escolar e profissional) a partir de um modelo, que se quis integrado, baseado num referencial de competências-chave (RCC) e assente no princípio transversal de iniciar cada curso EFA com base num reconhecimento e validação das competências (RVC) adquiridas previamente por cada adulto/formando. Tratou-se, no essencial, de procurar instituir um novo ponto de partida para os processos pedagógicos que envolviam os adultos, ambicionando-se superar "a dupla herança" (cf. Canário, cit. em ANEFA, 2002c, p. 50) que tem vindo a caracterizar a história recente da EA em Portugal, nomeadamente a da vertente escolarizante, que persistiu no ensino recorrente de adultos, e a da vertente da formação profissional, tendente a reproduzir uma perspetiva funcionalista da relação entre a formação e o trabalho. De acordo com Canário (cit. em ANEFA, 2002c), "estas duas tradições situam-se nos antípodas de uma formação que se pretende baseada na centralidade do sujeito que aprende, a partir do reconhecimento e validação de adquiridos experienciais e tendo como referência não uma listagem de conteúdos, mas sim um conjunto alargado de competências a construir" (p. 50). Neste sentido, toda a conceção curricular destes cursos, inovadora no setor, envolveu, e ainda envolve, um sistema modular criado "numa perspectiva de individualização e diferenciação dos trajectos de educação-formação, incluindo componentes integradas de formação profissionalizante e de formação de base que possibilitem a obtenção de uma certificação única" (ANEFA, 2002a, pp. 7-8) num dos três níveis básicos de certificação ${ }^{4}$ com que o projeto-piloto dos cursos EFA começaria por ser implementado no contexto português, vindo, depois de 2007, a estender-se ao nível secundário.

É de referir que o balanço público, resultante da análise dos primeiros 13 Cursos EFA em observação, foi apresentado, em 2002, como globalmente positivo, encorajando "o alargamento e consolidação progressivos deste novo tipo de oferta educativa, dirigido a públicos adultos não escolarizados ou cuja escolarização não cobre a educação básica obrigatória" (Canário, cit. em ANEFA, 2002c, p. 49). No que concerne à administração central desta nova 
oferta, há que destacar a adoção de um modelo que, de acordo com Trigo (2002b), "faz um convite e um apelo a todas as organizações da sociedade civil, acreditadas pelo INOFOR (Instituto para a Inovação na Formação), para desenvolverem cursos EFA" (p. 116) - o que neste âmbito representou, sobretudo, a indução clara de novas formas de governação educacional no setor.

No que respeita, por seu turno, à oferta de Ações $S @$ ber +, o que sobressaiu, desde o princípio, como mais característico, aqui, foi a estrutura destas ações de formação de curta duração, que foram concebidas, inicialmente, para abranger um vasto leque de domínios possíveis de formação, permitindo aos adultos usufruir de um ou mais módulos (de 50 horas cada) diferenciados entre si, por serem: ou de iniciação, ou de aprofundamento, ou de consolidação de conhecimentos (cf. ANEFA, 2001c, p. 31). A sua criação foi pensada como suporte às restantes ofertas, para atingir o objetivo de "desenvolver ou reforçar competências em domínios profissionais, escolares e pessoais" (ANEFA, 2001b, p. 45; 2002b, p. 37), cumprindo a estratégia geral afeta à criação do novo sistema EFA, designadamente: "promover a aprendizagem ao longo da vida, contribuindo para uma resposta eficaz às exigências da terciarização e do desenvolvimento económico" (ANEFA, 2001b, p. 45; 2002b, p. 37).

Por fim, no que diz respeito, por sua vez, à oferta de RVCC, o que sobressaiu desde a origem como mais característico foi, desde logo, o seu enquadramento numa estratégica que passou por assumir que "existe em Portugal uma subcertificação" (ANEFA, 2001c, p. 39), sendo por esta via justificada a criação de "duas grandes áreas de intervenção (...) [para] ser dada a oportunidade a todos os cidadãos e, em particular, aos menos escolarizados e aos activos empregados e desempregados de verem reconhecidas e certificadas as competências e conhecimentos que, nos mais variados contextos, foram adquirindo ao longo do seu percurso de vida" (ANEFA, 2001b, p. 21). Tratou-se, pois, por um lado, da arquitetação do sistema de RVCC, e, por outro lado, da construção, gradual, de uma rede de Centros de RVCC (reconvertidos em Centros Novas Oportunidades desde 2006). Assim, segundo Santos Silva (2002), competiria à ANEFA mobilizar-se extensivamente nesta matéria para intervir com base no princípio de que "é possível e necessário valorizar a experiência e as capacidades profissionais, 
além de pessoais e cívicas, dos adultos para melhorar também o seu nível educacional" (p. 73).

Foram, deste modo, prioridades da ANEFA, entre 1999 e 2002, desenvolver o essencial dos processos metodológicos inerentes ao sistema de RVCC, nomeadamente no que respeita: às bases do modelo de organização e intervenção inerente ao processo de RVCC; aos materiais específicos de apoio ao desenvolvimento estrutural e organizacional das práticas (exemplo dos kits para o processo de RVCC); aos diversos instrumentos diretos de apoio para os profissionais de RVCC e para os adultos em processo; aos dispositivos indiretos de apoio para uma documentação técnica/pedagógica adequada a todos os intervenientes no processo de RVCC; ou, ainda, à compilação e divulgação de materiais de suporte teórico ao processo de balanço de competências e à construção do dossier pessoal (ou portefólio) dos adultos (cf. ANEFA, 2001b, pp. 21-38; 2002b, pp. 19-23). A sua atividade neste domínio passou, concomitantemente, por estabilizar os procedimentos relativos: ao registo nacional de avaliadores externos; à definição da gestão técnico-pedagógica ${ }^{5}$ dos Centros com oferta de RVCC; e à acreditação de entidades potenciais promotoras de novos Centros de RVCC. Tudo isto foi feito com vista a conduzir, progressivamente, à consolidação futura do funcionamento nacional dos Centros de RVCC, que se pretendeu, alegadamente, em rede e numa lógica de parcerias.

De sublinhar é o facto que, inscrevendo-se esta oferta, em particular, numa linha de enfrentamento do problema da subcertificação, as orientações de política educativa teceram-se, talvez aqui de modo mais vincado, segundo linhas híbridas em que, reconhecendo-se o potencial do processo de RVCC para a "construção de oportunidades e percursos de formação congruentes com os trajectos e as aquisições passadas dos formandos" (Santos Silva, 2002, p. 142), se admitiria a necessidade de evitar que esta oferta se transformasse numa "atribuição administrativa de títulos escolares" (Santos Silva, 2002, p. 142), ao mesmo tempo que se redefiniriam as metas físicas (sempre irrealistas e exageradas) que cada Centro de RVCC teria de cumprir, em termos de certificação, para tornar este investimento eficaz no objetivo de contribuir para "recuperar, tão depressa quanto possível, o atraso acumulado" (Santos Silva, 2002, p. 141). Posto isto, ficam assim, no essencial, mapeadas as opções que sustentaram a estruturação nacional da nova oferta pública de EFA. 


\section{A governação pluriescalar do setor: 0 nível nacional}

Ora, ainda neste âmbito, e embora não tendo feito parte do núcleo central de atenção da ANEFA - de que fizeram também parte o lançamento de várias edições, publicações periódicas e materiais de informação e divulgação -, merecem-nos ainda uma referência especial duas intervenções, sobretudo por terem representado, segundo o nosso entendimento, duas tentativas concretas de expandir, numa lógica mais abrangente e democratizante do que aquela que se tornaria dominante, a nova oferta geral de EFA criada. Foram duas iniciativas com carácter muito mais efémero do que as anteriores (e que aqui desejamos propositadamente visibilizar), nomeadamente: a conceção de um quadro de referência para a criação futura da então prevista rede de Clubes S@ber +; e a realização das edições do Concurso Nacional S@ber +. Desta forma, se a primeira iniciativa pretendia investir na disseminação de espaços de convívio, acolhimento, informação e aconselhamento dos adultos, visando estimular, pela lógica de proximidade e informalidade, a sua participação em atividades de natureza educativa e cultural (cf. Melo, 2001), a segunda, de acordo com Alberto Melo, que presidiu aos concursos, afigurava-se como um concurso verdadeiramente estratégico com potencial para ativar ações complementares para um desenvolvimento pleno e alargado do setor, na medida em que

para além do conhecer e reconhecer, para lá do premiar e divulgar, é um facto que através desta actividade tem sido possível levar o nome, o programa e 'a maneira de estar' da ANEFA a um sem número de localidades e de entidades, que descobrem enfim o tão desejado interlocutor dentro do aparelho de Estado, para as matérias de educação de adultos [sendo igualmente importante que] reciprocamente, por parte da Agência Nacional, foi a descoberta do muito e do bom trabalho que se tem feito por esse país fora, a partir, muitas vezes, de organizações que se desconheciam ou de que não se suspeitava sequer que pudessem dedicar-se a actividades de natureza educativa com públicos adultos (Melo, cit. em ANEFA, 2001a, pp. 7-8)

O que releva daqui é essencialmente a base do nosso argumento que encontra contradições profundas entre os princípios mais humanistas, declarados na parte retórica dos discursos oficiais das políticas públicas recentes para o setor, e a sua parte programática, que, ao invés, desinveste precisamente nas intervenções com maior potencial emancipador. Por outras palavras, se era, de facto, numa política construtivista e humanista de EFA que se queria investir, então, entre outras e desde uma perspetiva crítica, 
estas duas linhas de intervenção prevista da ANEFA, que agora referenciamos, seriam forçosamente um eixo prioritário a desenvolver, na medida em que representavam uma via facilitadora de articulação e integração entre os pressupostos do mundo da educação e os pressupostos do mundo da formação.

Ora, se a este definhamento de linhas promissoras inicialmente previstas no âmbito do Programa de Acção S@ber + (já recomendadas, inclusive, pelas Propostas e Relatórios que o precederam) como parte das atribuições de uma "ANEFA imaginada" (cf. Lima, 2001, pp. 55-56) juntarmos os retrocessos já substantivamente visíveis na "ANEFA decretada" (DecretoLei n. ${ }^{\circ} 387 / 99$, de 28 de setembro), que se agudizariam na ação da "ANEFA materializada" - que, tendo sido criada em regime de instalação, foi extinta (Despacho 21974/2002, de 25 de setembro, e Decreto-Lei n. ${ }^{\circ}$ 208/2002, de 17 de outubro) ainda antes de ter sido efetivamente instalada -, então a disseminada retórica de desenvolvimento e expansão do campo da EFA pelo novo sistema EFA transformar-se-á, afinal (por via de uma análise crítica de desocultação), num mero mecanismo de legitimação de um novo tipo de produção de políticas sociais, que compreenderiam o setor, próprias de um Estado ainda profundamente heterogéneo (Sousa Santos, 1993), que atribuiu sobretudo um mandato económico às políticas educacionais.

Neste âmbito, o uso do conceito de 'governação pluriescalar' (Barros, 2009) pretende captar as lógicas ambivalentes com que se jogam hoje interesses múltiplos e transnacionais na decisão política em educação. É uma categoria teórica para apreender as complexas dimensões da governação em contexto de globalização político-económica neoliberal, particularmente em contexto europeu e desde a Agenda de Lisboa, privilegiando uma abordagem sociológica que entrecruza os diversos níveis analíticos (mega, macro, meso e micro). Pretende-se, com este contributo, que as várias escalas inter-relacionadas de governação da nova EFA (supranacional, nacional e subnacional) e os respetivos atores institucionais principais fiquem melhor evidenciados.

De acordo com Roger Dale (2005), a governação da educação é, na atualidade, um assunto pluriescalar quer porque "potencialmente tem lugar em várias escalas, e não apenas ao nível do Estado-nação" (p. 63), quer porque "não é internacional, com as suas implicações de múltiplas 
localizações (tipicamente Estados-nação) na mesma escala" (p. 63). Nas palavras deste autor,

O que estamos agora a testemunhar é não apenas um desvio do Estado, que assume a responsabilidade directa por todas as actividades, e da própria regra para o Estado que determina quem assumirá a responsabilidade por elas, mas que as combinações à escala nacional de actividades [financiamento, posse, fornecimento e regulação] e instituições [Estado, Mercado, Comunidade e Família] de governação têm de ser aumentadas pelo reconhecimento de que, potencialmente, qualquer uma ou todas estas actividades podem também ser geridas a uma escala diferente [supranacional, nacional e subnacional] (Dale, 2005, p. 63).

Neste texto discutimos alguns aspetos mais relacionados com o nível nacional desta matriz de governação educacional pluriescalar, emergente no nosso contexto em 1999 e hoje claramente consolidada, que, sustentamos, teve na ANEFA um ator institucional estratégico ímpar.

Deste modo, o Estado português democrático - que, a nosso ver, apresenta características híbridas de Estado semiprovidência e de Estado semineoliberal -, veio, pois, a desenvolver uma agenda política educacional também ela profundamente ambivalente. À nova EFA foi sobretudo conferido um mandato económico - que, de resto, se explicita, num primeiro momento, ao nível de um agendamento desta área por via dos compromissos assumidos pelo Estado a nível supranacional, intercetando depois, num segundo momento, a nível da tomada de decisão política nacional, as prioridades políticas conjunturais com as recomendações nacionais de comissões e grupos de trabalho (de resto, neste domínio, entusiasticamente, e ciclicamente, criados para o efeito), indo-se desembocar num terceiro momento de desvinculação tácita dos processos desencadeados no momento precedente, em que se dá, no decurso da execução, uma inflexão profunda das orientações públicas concertadas na fase intermédia deste novo modo reescalonado de governação educacional, agora operante.

Trata-se, a nosso ver, de um novo processo de índole transnacional de elaboração de políticas públicas educacionais, que já foi designado também de "governação sem governo" (Rosenau \& Czempiel, 1992), que emerge em Portugal coincidentemente com o novo ciclo de governação socialista (do XIII e XIV Governos Constitucionais) e que, para este subsistema em particular, teve na ANEFA a nova instituição de sustentação a nível nacional. É nesse 
sentido, parece-nos, que o seu papel na governação pluriescalar da nova EFA pode ser interpretado como uma porta giratória que (des)ligou os interesses de entidades supranacionais (tais como a EU, a OCDE, o BM, ou os industriais europeus) dos interesses de entidades subnacionais (materializadas na rede de novas entidades promotoras de EFA). Ou seja, a montante e a jusante das realizações efetivas resultantes do seu, curto mas decisivo, período de existência.

Assim, não estando em causa o seu evidente potencial de intervenção para fazer surgir novas paisagens educativas num campo educacional excessivamente afunilado no contexto português (Lima, 2005; Barros, 2011a; Guimarães, 2011), o que sobressaiu da sua missão mais geral envolveu, de um lado, um contributo efetivo para reestruturar o modelo de regulação social ajudando a implementar uma redefinição dos papéis do Estado, agora cada vez mais regulador e articulador, do Mercado, renovado num quase-mercado, e da sociedade civil, transfigurada num terceiro setor de parceiros sociais (Antunes, 2011b). Isto é, operando, a montante, através de um papel ativo de introdução de novas formas de governação educacional a nível nacional, que potenciou a rápida admissão, no campo, de novas combinações institucionais, assentes maioritariamente em contratos-programa, mas também na figura do partenariado e, sobretudo, num notório investimento para criar uma miríade de entidades promotoras como elementos estratégicos de uma nova ordenação dos processos e das relações sociais para a educação e formação de adultos.

De outro lado, sobreleva também como parte integrante da sua missão, mais vasta e geral, o contributo efetivo que foi dado para a prossecução interna de metas e objetivos definidos transnacionalmente (com destaque para as linhas de ação baseadas nos indicadores produzidos pela OCDE e pela UE, periodicamente publicados), que, para o presente caso, representam sinais da emergência de uma nova ordem educacional mundial, mais significativa, porém, para o contexto português na sua vertente de europeização das políticas educativas nacionais para o subsistema da educação de adultos. Ou seja, operando, a jusante, através de um papel ativo de prolongamento de novas formas de governação educacional situadas a nível supranacional, que abriram caminho para a plena introdução, na agenda política, de um novo domínio-tríplice que inter-relaciona educação, formação 
e empregabilidade, e de uma nova lógica de fazer políticas públicas, protagonizada pela União Europeia e particularmente assente no novo método aberto de coordenação (MAC), que, produzindo instrumentos comuns de governação para o espaço europeu, parece ter contribuído decisivamente, e discretamente, para a emergência de um novo sistema político de múltiplos níveis (Pierson \& Leibfried, 1995).

Defendemos, portanto, que se operou em Portugal, durante a segunda década de integração europeia (entre 1996 e 2006), e deste modo politicamente inovador e complexo, uma verdadeira viragem no campo da, tradicionalmente conceptualizada, EA. Uma viragem que tem vindo a estar profundamente inscrita numa ampla e silenciosa revolução política que, ao contrário do que se afirma publicamente através dos circuitos e produtos das instâncias internacionais dominantes (Comissão Europeia, 2000), tem sido vivamente e principalmente ideológica (com o neoliberalismo a representar a força motriz deste processo).

Parece-nos, neste sentido, que a ANEFA desempenhou um macro papel-chave no arranque nacional, em 1999, da governação pluriescalar da nova EFA, que desde 2006 e a Iniciativa Novas Oportunidades opera consolidadamente no setor. Neste processo, não foi indiferente, quanto a nós, o facto, sublinhado por Melo, Lima, e Almeida (2002), de a ANEFA parecer observando-se o seu desempenho - ter sido "concebida como uma estrutura de mediação, e nalguns casos, talvez de regulação, de iniciativas que relevam de intervenções dos domínios da educação e do trabalho, e da formação profissional" (p. 118). Por outras palavras, este seu "papel de indutora indirecta" (Melo et al., 2002, p. 120) parece-nos ter sido, inclusivamente, funcional a um processo político de natureza nova, transnacional mas ainda emergente (e nesta fase ainda pouco percetível), de transformação das políticas públicas setoriais de educação - aliás, desde sempre fragmentadas para o campo da educação de adultos nacional - em algo substantivamente diverso: as novas estratégias de planeamento para a educação e formação de adultos, que poderia ser, supomos, mais logicamente (ou pelo menos mais transparentemente) qualificado de processo pluriescalar de criação de políticas de emprego e formação de ativos (um outro possível entendimento para as 'políticas de EFA'). 
Argumentamos, pois, que, como elemento propiciador do arranque nacional da governação pluriescalar da nova EFA, tanto para o nível subnacional (que envolve as entidades promotoras do terceiro setor e as equipas técnicas) como para o nível supranacional (que envolve as instâncias internacionais e os seus instrumentos de financiamento) da sua escala de organização, a atuação da ANEFA foi fundamental. Em especial, as marcas sociopolíticas deixadas na formação social portuguesa pela sua clara e assumida pretensão de instituir um novo contrato social em torno do setor (Trigo, 2002a) revelar-se-iam ser, não só estratégicas para os desenvolvimentos subsequentes a nível da consolidação de uma nova lógica nas modalidades de provisão educativa para adultos (reformulando as próprias atividades de governação educacional), como, inclusive, permitiriam, igualmente, legitimar uma mais vasta reformulação do papel do Estado de bem-estar (cada vez mais mitigado) na área da produção das políticas sociais (Barros, 2012). Tudo isto, através da celebração de uma nova retórica, tornada hegemónica a nível nacional pelas várias tutelas institucionais da nova EFA 6 , em torno da ideia da participação alargada dos parceiros sociais na decisão política - uma ideia que, de resto, o modelo do partenariado social parece facilmente contribuir para validar e expandir a nível discursivo (Marques, 1994).

Ora, sendo Portugal um país da semiperiferia europeia caracterizado, no essencial, por deter um Estado forte e centralizado, um mercado fraco e díspar, e uma sociedade civil simultaneamente forte na provisão social compensatória e fraca na sua organização cívico-política reivindicativa, a nova combinação organizacional assente na figura do partenariado, avançado como sinónimo de participação (cf. Antunes, 1998), seria, na nossa ótica, construída com uma dupla finalidade em que se observam os mecanismos e a nova divisão funcional e escalar do trabalho da governação educativa neste setor: por um lado, a finalidade de legitimar no sistema político os projetos centrais, neste caso de índole educacional, mediante a sua (pretensamente democrática) assunção por parte de organizações e instituições periféricas da sociedade civil; e, por outro lado, a finalidade de contribuir para substituir a conflitualidade de interesses plurais por uma negociação cooperante, neste sentido habilitando-nos a compreender os motivos pelos quais "o partenariado socioeducativo surge como uma estratégia (instrumento) de cooperação 
numa perspectiva sistémica de relação sistema educativo/sistema económico e social" (Marques, 1994, p. 50). Deste modo, o partenariado foi, em boa medida, imposto por iniciativa do próprio poder estatal e, de acordo com Antunes (2001), "como forma de promover intervenções capazes de superar alguns impasses e obstáculos e de promover formas de actuação congruentes com condições e objectivos valorizados" (p. 183).

Desde a nossa perspetiva, os novos atores e entidades (que agora participam legitimamente neste processo de governação como coordenação da coordenação) têm vindo a contribuir, sobretudo, para uma redistribuição de responsabilidades na elaboração de políticas públicas educacionais, permitindo, indiretamente, redirecionar os termos segundo os quais se conferiu uma nova ênfase à EFA, como ilustra a forma como foi assumida a importância deste subsistema no âmbito do Acordo de Concertação sobre Política de Emprego, Mercado de Trabalho, Educação e Formação assinado em 2001, em que se estabeleceram diversas medidas de incremento da EFA, tais como a consolidação da oferta de cursos EFA, da oferta de RVCC e da oferta de formação contínua de ativos empregados com mínimos obrigatórios de frequência anual de formação, constituindo um conjunto de medidas entendidas, na essência, como contributos para um esforço de promoção da escolarização e formação profissional, bem como da qualidade de emprego e da aceitação de políticas sociais ativas (cf. Conselho Económico e Social, 2001).

\section{Considerações finais}

O tipo de interpretação que ao longo deste texto propusemos para o papel da ANEFA, no âmbito do arranque nacional da governação pluriescalar da nova EFA, pode servir de ilustração para o que Licínio Lima (1997, p. 53) identificou como um movimento intermitente de recentralização/ /descentralização e de regulação/desregulação que surgem como formas de concentrar e controlar centralizadamente os poderes de decisão e de escolha política e de, simultaneamente, descentralizar em termos meramente funcionais decisões de tipo predominantemente instrumental e operacional nos níveis periféricos. 
De facto, seria esta a lógica que caracterizaria, desde então, a nova forma de governação educacional do setor que, a nível nacional, assentou na ideia estruturante de que o papel do Estado na modernização do país consistiria, sobretudo, em promover a criação de "operadores estratégicos de formação" (cf. Mesquita, 2000). Assim, o Estado capitalista democrático português assumiu-se, embora seguindo, como referimos, linhas de orientação ideológica híbridas entre um padrão humanista e um padrão neoliberal, como Estado articulador de uma crescente rede de entidades promotoras de EFA - na época aqui considerada, criadas por mediação da ANEFA, numa fórmula política compósita em que coube ao Estado a regulação ${ }^{7} \mathrm{e} o$ financiamento 8 da oferta de EFA e à nova rede de promotores (públicos e privados) a propriedade 9 e o fornecimento ${ }^{10}$ dessa mesma oferta. Foram estas as instituições de coordenação social, para o nível nacional, mais particularmente envolvidas em cada uma destas quatro atividades de governação educacional (Dale, 2005) de uma nova ordem educacional emergente, que foi o resultado direto do envolvimento ativo do Estado, aqui analisado por via do seu empenho na construção de um subsistema não formal de EFA.

Assim, as tensões próprias dos Estados capitalistas democráticos (Offe, 1984) parecem ter sido confrontadas pelo Estado semiperiférico português segundo uma agenda contraditória que, de um lado, encarou e assumiu a necessidade de relançar e expandir um campo educativo excessivamente afunilado e, de outro lado, anuiu na prioridade à competitividade nacional e aos requisitos necessários à adoção europeia de um novo modelo de desenvolvimento económico assente na indústria da informação e do conhecimento.

A força do mandato europeu (ancorada na ideia de uma imprescindível articulação entre educação, formação e emprego) fez, assim, reajustar as vertentes prioritárias de intervenção segundo as quais a ANEFA edificou toda esta nova oferta educativa nacional. Tratou-se igualmente, segundo a nossa ótica, de um exemplo da influência dos efeitos externos indiretos da globalização (Dale, 2001, 2005) a justificar a reinscrição do setor na agenda política do Governo socialista (vigente entre 1995 e 2002) para permitir, afinal, concretizar um projeto de transição sociopolítica mais vasto (Griffin, 2002), e globalmente estruturado, em que a conceção de temáticas tradicionais do 
âmbito das políticas de educação de adultos (as "velhas políticas" de EA) passa por uma reconceptualização dos mesmos temas vistos agora como problemáticas inscritas no âmbito das estratégias de emprego e formação (as "novas políticas" de EFA).

Parece-nos, pois, ser possível interpretar neste sentido o facto, já assinalado por Licínio Lima (2005), de que, na atuação da ANEFA, "as lógicas modernizadoras, de simples indução e, especialmente, de qualificação de recursos humanos, subordinadas à empregabilidade e à aquisição de competências para competir, predominaram claramente sobre outras vertentes que estavam presentes nos projectos iniciais para a ANEFA" (p. 48). Como resultado do papel ativo da ANEFA no prolongamento nacional de novas formas de governação educacional situadas a nível supranacional, constatou-se, tal como tem vindo a acontecer a nível europeu, que predominou (embora não ao nível da retórica discursiva, talvez ainda mais humanista do que antes) um entendimento paliativo ${ }^{11}$ para a missão que as atividades públicas de educação e formação dirigidas a adultos deveriam desempenhar - o que, em parte, explica que, na ANEFA, se tivesse verificado, como sublinha Lima (2005), que

a indução predominou sobre a intervenção, a 'lógica de programa' inibiu a 'lógica de serviço público', a anunciada política de desenvolvimento foi limitada à produção de orientações estratégicas com vista à criação de condições de intervenção de terceiros, tal como a anunciada articulação entre educação e formação cedo veio a revelar a subordinação da primeira às agendas da segunda (pp. 48-49).

Ou seja, o que este pequeno ensaio sobre o papel que a ANEFA teve pretendeu ilustrar foi o momento da emergência da europeização das políticas educativas nacionais para o setor, num processo em que a governação da educação passa, a partir de agora, a ser um assunto pluriescalar, como aqui se demostrou, que esteve e está repleto de tensões e ambivalências que se impõe continuar a investigar (tendo, portanto, em conta outras escalas para além da nacional) sempre com criticidade e posicionamento. 


\section{Notas}

1 De que são exemplo o Plano Nacional de Alfabetização e Educação de Base dos Adultos (PNAEBA) (1979) ou o Relatório da Comissão de Reforma do Sistema de Ensino (CRSE) (1988).

2 Relembre-se aqui o continuum do modelo teórico proposto e apresentado noutro lugar (Barros, 2011b) acerca da conceptualização do campo da educação de adultos, que pode oscilar entre um conceito predominantemente emancipatório, mais próximo do que designámos por uma cultura de problemas, que orienta práticas regidas pelo princípio da reciprocidade, e um conceito predominantemente regulador, mais próximo do que designámos por uma cultura de respostas, que orienta práticas regidas pelo princípio da competitividade.

3 O Despacho Conjunto n. ${ }^{\circ}$ 156/2002, de 1 de março (DR n. ${ }^{\circ}$ 51, II Série), viria a prorrogar, excecionalmente, até ao limite de um ano o período de instalação da ANEFA, terminado em 28 de setembro de 2001.

4 No arranque deste sistema, o Certificado de EFA era de três tipos: Básico 1 (B1), equivalente ao $1^{\circ}$ Ciclo do Ensino Básico e ao Nível I de Qualificação Profissional; Básico 2 (B2), equivalente ao $2^{\circ}$ Ciclo do Ensino Básico e ao Nível I de Qualificação Profissional; ou Básico 3 (B3), equivalente ao $3^{\circ}$ Ciclo do Ensino Básico e ao Nível II de Qualificação Profissional.

5 Tratou-se sempre, desde esta altura, de uma complexa gestão "técnicopedagógica", na realidade mais financeira do que pedagógica, exigida pela gestão nacional do PRODEP III, em conformidade com o Despacho Conjunto n. ${ }^{\circ}$ 262/2001, de 22 de março.

6 O que representa uma característica transversal tanto à ANEFA, entre 1999 e 2002, como à DGFV (Direção-Geral de Formação Vocacional), entre 2002 e 2006, como à ANQ (Agência Nacional para a Qualificação), entre 2006 e 2011, e à atual ANQEP (Agência Nacional para a Qualificação e o Ensino Profissional).

7 Embora aqui em articulação com a própria ANEFA, para estipular a definição geral de normas e critérios genéricos organizadores das especificidades da nova oferta.

8 O financiamento tem sido predominantemente público, mas comportando uma significativa parcela de cofinanciamento supranacional proveniente dos Fundos Estruturais da União Europeia.

9 As entidades promotoras devem pertencer previamente à lista de entidades registadas no INOFOR, de modo a garantir-se a existência e posse dos recursos necessários ao desenvolvimento adequado de ações educativo-formativas.

10 Tendo, neste período, o Estado e a ANEFA previamente estipulado competências e âmbitos de atuação, coube autonomamente às entidades promotoras, respeitando os termos do designado dossier de gestão técnico-pedagógica, assegurar o provimento dos novos serviços educativo-formativos destinados aos adultos.

$11 \mathrm{Na}$ verdade, percecionamos aqui um entendimento ainda mais restrito do que antes, para o setor, celebrado, desde então, ora numa visão instrumentalizada, como no caso expresso pelo Acordo social de 2001, ora numa visão assistencialista, como no caso manifesto da sua afetação a medidas sociais ditas ativas. 


\section{Referências}

ANEFA (2001a). Concurso nacional S@bert: Projectos premiados 2000 (Vol. II). Lisboa: ANEFA.

ANEFA (2001b). Plano de actividades 2001. Lisboa: ANEFA.

ANEFA (2001c). Relatório de actividades 2000. Lisboa: ANEFA.

ANEFA (2002a). Cursos de educação e formação de adultos - Documento de trabalho. Lisboa: ANEFA.

ANEFA (2002b). Plano de actividades 2002. Lisboa: ANEFA.

ANEFA (2002c). Relatório nacional - Cursos de educação e formação de adultos "em observação" 2000/2001. Lisboa: ANEFA.

Antunes, F. (1998). Políticas educativas para Portugal, anos 80-90 - O debate acerca do ensino profissional na escola pública. Lisboa: Instituto de Inovação Educacional.

Antunes, F. (2001). Os locais das escolas profissionais: Novos papéis para o Estado e a europeização das políticas educativas. In S. Stoer, L. Cortesão \& J. A. Correia (Org.), Transnacionalização da educação - Da crise da educação à "educação" da crise (pp. 163-208). Porto: Edições Afrontamento.

Antunes, F. (2011a). Educação de adultos e ao longo da vida - Da política ao planeamento, um terreno de acção e lutas políticas. Revista A Página da Educação, 194, 36-37.

Antunes, F. (2011b). Governação, reformas do Estado e políticas de educação de adultos em Portugal: Pressões globais e especificidades nacionais, tensões e ambivalências. Revista Crítica de Ciências Sociais, 92, 3-29.

Barros, R. (2009). Políticas para a educação de adultos em Portugal - A governação pluriescalar da "nova educação e formação de adultos" (1996-2006) (Tese de Doutoramento não publicada). Universidade do Minho, Braga.

Barros, R. (2011a). A criação do reconhecimento de adquiridos experienciais (RVCC) em Portugal - Uma etnografia crítica em educação de adultos. Lisboa: Chiado Editora.

Barros, R. (2011b). Genealogia dos conceitos em educação de adultos: Da educação permanente à aprendizagem ao longo da vida - Um estudo sobre os fundamentos político-pedagógicos da prática educacional. Lisboa: Chiado Editora.

Barros, R. (2012). Subsídios breves para o debate de princípios e valores na formação política do(a) educador(a) social. Lisboa: Chiado Editora.

Caride, J. A., Peres, A., Sanjurjo, L., Ortega, R., \& Pose, H. (2009). Los derechos humanos en la educación y la cultura: Del discurso político a las prácticas educativas. Argentina: Editorial HomoSapiens.

Castro, R. V., Sancho, A., \& Guimarães, P. (2006). Adult education in Portugal: Ways of thinking and ways of doing. In R. V. Castro, A. V. Sancho \& P. Guimarães (Eds.), Adult education - New routes in a new landscape (pp. 189-230). Braga: Unidade de Educação de Adultos/Universidade do Minho. 
Comissão Europeia (2000). Memorando sobre aprendizagem ao longo da vida. Luxemburgo: Serviço das Publicações Oficiais das Comunidades Europeias.

Conselho Económico e Social (2001). Acordo sobre política de emprego, mercado de trabalho, educação e formação. Lisboa: CES.

Conselho Nacional de Educação (2000). Educação intercultural e cidadania - Actas do Seminário. Lisboa: CNE/Ministério da Educação.

Dale, R. (2001). Globalização e educação: Demonstrando a existência de uma 'cultura educacional mundial comum' ou localizando uma 'agenda globalmente estruturada para a educação'? Educação, Sociedade e Cultura, 16, 133-169.

Dale, R. (2005). A globalização e a reavaliação da governação educacional. Um caso de ectopia sociológica. In A. Teodoro \& C. A. Torres, Educação crítica e utopia. Perspectivas para o século XXI (pp. 53-69). Porto: Edições Afrontamento.

Griffin, C. (2002). From education policy to lifelong learning strategies. In P. Jarvis (Ed.), The age of learning - Education and the knowledge society (pp. 41-54). London: Kogan Page.

Guimarães, P. (2008). A educação de adultos no séc. XXI: Desafios contemporâneos em prospectiva [documento policopiado]. Trabalho apresentado no Encontro Internacional "Escola d'Estiu'08 - Una educació per als homes í dones del s.XXI", Barcelona.

Guimarães, P. (2011). Políticas de educação de adultos em Portugal (1999-2006) - A emergência da educação e formação para a competitividade. Braga: Universidade do Minho/Instituto de Educação.

Lima, L. (1997). O paradigma da educação contábil - Políticas educativas e perspectivas gerencialistas no Ensino Superior em Portugal [documento policopiado]. Trabalho apresentado na XIX Reunião Anual da ANPEd, Caxambu.

Lima, L. (2000). Portugal - Historical background. In P. Jarvis (Ed.). Perspectives on adult education and training in Europe (pp.1-19). Leicester: NIACE.

Lima, L. (2001). Políticas de educação de adultos: Da (não) reforma às decisões pósreformistas. Revista Portuguesa de Pedagogia, 35(1), 41-66.

Lima, L. (2005). A educação de adultos em Portugal (1974-2004): Entre as lógicas da educação popular e da gestão de recursos humanos. In R. Canário \& B. Cabrito (Org.), Educação e formação de adultos - Mutações e convergências (pp. 3160). Lisboa: EDUCA-Formação.

Lima, L., Afonso, A., \& Estêvão, C. (1999). Agência Nacional de Educação de Adultos Estudo para a construção de um modelo institucional. Braga: Unidade de Educação de Adultos/Universidade do Minho.

Marques, M. (1994). A decisão política em educação. O partenariado sócio-educativo como modelo decisional - $O$ caso das escolas profissionais. Porto: Edições Afrontamento.

Melo, A. (2001). Uma nova vontade política de relançar a educação e formação de adultos? In A. Teodoro (Org.), Educar, promover, emancipar - Os contributos de Paulo Freire e Rui Grácio para uma pedagogia emancipatória (pp. 101-120). Lisboa: Edições Universitárias Lusófonas. 
Melo, A. (2003). A ausência de uma política de educação de adultos como forma de controlo social e alguns processos de resistência [documento policopiado].

Melo, A. (2006). Is there a right to development? [documento policopiado].

Melo, A., Lima, L., \& Almeida, M. (2002). Novas políticas de educação e formação de adultos - O contexto internacional e a situação portuguesa. Lisboa: ANEFA.

Melo, A., Matos, L., \& Silva, O. S. (2001). S@ber +: Programa para o desenvolvimento e expansão da educação e formação de adultos, 1999-2006. Lisboa: ANEFA/GMEFA.

Mesquita, L. (2000). Educação e desenvolvimento económico - Contribuição para o estudo da natureza presente de uma relação. Lisboa: Instituto de Inovação Educacional.

Offe, C. (1984). Problemas estruturais do Estado capitalista. Rio de Janeiro: Tempo Brasileiro.

Pierson, P., \& Leibfried, S. (1995). Multitiered institutions and the making of social policy. In S. Leibfried \& P. Pierson (Eds), European social policy: Between fragmentation and integration. Washington D. C.: The Brookings Institution.

Rosenau, J., \& Czempiel, E. (1992). Governance without government: Order and change in world politics. Cambridge: Cambridge University Press.

Rothes, L. (2005). Recomposição induzida do campo da educação básica de adultos Lógicas de apropriação local num contexto político-institucional redefinido (Tese de Doutoramento). Universidade do Porto, Porto.

Santos Silva, A. (1996). Funções, estilos, parceiros e lugares da educação extraescolar. In M. F. Guerra \& M. I. Teles (Org.), Funções, estilos, parceiros e lugares da educação extra-escolar (pp. 11-18). Lisboa: Ministério da Educação.

Santos Silva, A. (2002). Por uma política de ideias em educação. Porto: Edições ASA.

Sousa Santos, B. (1993). O Estado, as relações salariais e o bem-estar social na semiperiferia: O caso português. In B. Sousa Santos (Org.), Portugal: Um retrato singular (pp. 15-56). Porto: Edições Afrontamento.

Teodoro, A., \& Aníbal, G. (2006). A educação em tempos de globalização Modernização e hibridismo nas políticas educativas em Portugal [documento policopiado].

Trigo, M. M. (2002a). A ANEFA no quadro do PNE. In I. M. Silva, J. A. Leitão \& M. M. Trigo (Org.), Educação e formação de adultos - Factor de desenvolvimento, inovação e competitividade (pp. 132-134). Lisboa: ANEFA.

Trigo, M. M. (2002b). Balanço de um ano de actividade. In I. M. Silva, J. A. Leitão \& M. M. Trigo (org.). Educação e formação de adultos - Factor de desenvolvimento, inovação e competitividade (pp. 115-119). Lisboa: ANEFA.

UNESCO (1976). Recommendation on the development of adult education - General conference, Nairobi. 


\section{Outros documentos}

Decreto-Lei n. ${ }^{\circ}$ 208/2002, de 17 de outubro.

Decreto-Lei n. ${ }^{\circ} 387 / 99$, de 28 de setembro.

Despacho 21974/2002, de 25 de setembro.

Despacho Conjunto n. ${ }^{\circ}$ 1092/2000, de 24 de novembro (DR n. ${ }^{\circ} 272$, II Série).

Despacho Conjunto n. ${ }^{\circ} 1112 / 2000$, de 29 de novembro (DR n. ${ }^{\circ} 276$, II Série).

Despacho Conjunto n. ${ }^{\circ} 1113 / 2000$, de 29 de novembro (DR n. ${ }^{\circ} 276$, II Série).

Despacho Conjunto n. ${ }^{\circ} 1114 / 2000$, de 29 de novembro (DR n. ${ }^{\circ} 276$, II Série).

Despacho Conjunto n. ${ }^{\circ}$ 156/2002, de 1 de março (DR n. ${ }^{\circ} 51$, II Série).

Despacho Conjunto n. ${ }^{\circ}$ 262/2001, de 22 de março.

Lei n. ${ }^{\circ} 46 / 86$, de 14 de outubro.

Programa do XIV Governo Constitucional - Apresentação e Debate (2000). Lisboa: Assembleia da República/Divisão de Informação Legislativa e Parlamentar.

Resolução do Conselho de Ministros n. ${ }^{\circ}$ 92/98, de 25 de junho. 
NATIONAL INSTITUTE FOR ADULT EDUCATION AND TRAINING (ANEFA): A LANDMARK ON THE EUROPEANISATION OF THE PUBLIC AGENDA IN THE SECTOR

\begin{abstract}
The paper presents the sociopolitical framing where the first National Institute for Adult Education and Training (ANEFA) was created. We prove that ANEFA has been essential to the present development of this educational sector. Then we argue that the role of ANEFA was related to introduce, in national context, a new regulatory logic that has established a pluriscaled governance of adult education and training.
\end{abstract}

Keywords

Adult education; New educational offers; Pluriscaled governance; Educational policies 
AGENCIA NACIONAL DE EDUCACIÓN Y FORMACIÓN DE PERSONAS ADULTAS (ANEFA): UN PUNTO DE REFERENCIA EN LA EUROPEIZACIÓN DE LA AGENDA PÚBLICA EN EL SECTOR

\section{Resumen}

El texto presenta el contexto sociopolítico en que se creó la primera Agencia Nacional de Educación y Formación de Personas Adultas (ANEFA). Se demuestra que su actuación ha sido fundamental para el desarrollo del campo. Argumentamos que su papel ha sido el de introducir, en el contexto portugués, las bases transnacionales de la gobernación pluriescalar que, sostenemos, es la principal característica actual del sector.

Palavras clave

Educación de personas adultas; Nuevas ofertas educativas; Gobierno pluriescalar; Políticas educativas

Recebido em Outubro/2011 Aceite para publicação em Setembro/2012 